\title{
Code- Switching as a Language Teaching Strategy Based on the Grammar- Translation Method for Comprehension Enhancement
}

\author{
Aljun Araneta Desoyo \\ Department of Education, Faculty of Tanauan School of Craftsmanship and Home Industries, Tanauan, Leyte, Philippines \\ Email address: \\ aljundesoyo1992@gmail.com \\ To cite this article: \\ Aljun Araneta Desoyo. Code- Switching as a Language Teaching Strategy Based on the Grammar- Translation Method for Comprehension \\ Enhancement. International Journal of Applied Linguistics and Translation. Vol. 7, No. 1, 2021, pp. 1-20. doi: 10.11648/j.ijalt.20210701.11
}

Received: December 7, 2020; Accepted: December 24, 2020; Published: March 22, 2021

\begin{abstract}
This study aimed to determine the effectiveness of code- switching as a language strategy anchored on the grammar- translation method for comprehension enhancement to the grade seven junior high school students at Tanauan School of Craftsmanship and Home Industries, Tanauan, Leyte. It lasted for four (4) weeks from February 12 to March 12 , 2019 using the 60 grade 7 students enrolled during the school year 2018-2019. The 60 students comprised the four sections belonging in the heterogeneous group and were then divided into comparable groups of 15 students per section: the control group and experimental group. The control group was exposed to the English-only-policy method while the experimental group was exposed to the code- switching strategy taught by the English teachers. To find the effectiveness of the codeswitching strategy, the true-experimental design was used, employing the pre-test and post-test scheme. Since the experiment aimed to investigate the effectiveness of code- switching, in comparison with the English-only-policy approach, there was a need to measure achievement through fifty (50) item pre- test and post- test. Mean ratings of the students in both groups in the achievement test were analyzed. The findings showed that the achievement of the control and experimental group was the same in the pre-test; teaching capitalization was satisfactory, teaching punctuation, grammar and sentence structure was fairly satisfactory, and teaching word usage was satisfactory. The computed t- values were all not significant. The performance of both groups in the evaluations was very satisfactory but the experimental group showed a better performance than the control group. The results of the post-test of the control group were teaching capitalization was very satisfactory; teaching punctuation was very good; teaching grammar, teaching sentence structure and teaching word usage were very satisfactory; and the combination was very satisfactory. In the experimental group: teaching capitalization, teaching punctuation and teaching grammar were outstanding; teaching sentence structure and teaching word usage were very satisfactory; and the combination was outstanding. The computed t-values in teaching word usage was not significant, teaching capitalization, punctuation, grammar, and sentence structure were significant, while the combination was also significant at 0.05 level of significance. The performance of both groups in the pre-and post-tests along the five language competencies tested is found to be "significant".
\end{abstract}

Keywords: Code- Switching, Mother Tongue, English Only Policy, Language Teaching Strategy, Grammar- Translation Method

\section{Introduction}

The English language has become a fundamental part in the society as it is considered the international language that is used among non-native speakers around the globe. The ability of learning the language has been held as one of the most important competencies needed by the Philippines to reach its goal of being able to compete effectively with other nations.

In the Philippine Educational Setting, the Department of Education further enriched and deepened student's learning through the Enhance Basic Curriculum of 2013 or Republic Act No. 10533 which denotes that:

"The State shall establish, maintain, and support a complete, adequate and integrated system of education relevant to the needs of the people, the country, and the 
society-at-large. Furthermore, make education learneroriented and responsive to the needs, cognitive, and cultural capacity, the circumstances and diversity of learners, schools and communities through the appropriate languages of teaching and learning, including mother tongue as a learning resource."

As a multilingual race, English is considered the second language by Filipinos. However, in both rural and urban scenarios, mixing the foreign language with the vernacular becomes a habitual activity. As established, in the various regions of the nation, the Filipino language includes several dialects spoken. In the Philippine sense, however, the use of English both in written and oral communication becomes a traditional socio-linguistic language in order to sound more formal and dignified.

Using English in classrooms, a learner may progressively begin to create and form an identity as a consumer of the English language or the first language of interaction. While the policy in English language institutions allows English teachers and students to use only English in teaching, the actual practice in the classroom can differ. A teacher uses various strategies and methods to effectively teach the students. One of the strategies employed by teachers is codeswitching anchored on the grammar- translation method.

The method of grammar-translation is a method of teaching foreign languages derived from the classical method, often referred to as the conventional teaching method. Students study grammatical regulations in grammartranslation classes and then apply those rules by translating sentences between the target language and the native language. On the other hand, code-switching is the way of switching between languages in different settings, ideas, and statements. In education, code-switching is the process in which teachers switch between the first language and the second language for learners to learn the second language. Language learners learn and practice the target language in communicative language teaching environments by communicating with each other and the teacher, researching "authentic texts" written in the target language for reasons other than language learning, and using the language both in the classroom and outside the classroom. According to the communicative approach, the importance of factors such as connectivity and the role concerned must be stressed in order for learning to take place.

Since the code- switching is the method to be used in enhancing student's comprehension of this study, the basic language competencies will be the main subjects or target of allowing students to improve their understanding of the target language.

As stipulated in the English 7 Teacher's Guide, the lesson deals most with the basic language competencies: capitalization, punctuation, grammar, sentence structure, and word usage. These allow students to know and comprehend the information that is required of them as well as to gain a strong foundation in learning and even mastering the English language. Since these elements are separated by the learning outcomes, language competence can be established by classroom learning experiences that concentrate on meaningful uses of language and on contextual language. Based on the desires, preferences, and perspectives of students, assignments will be selected. As students are interested in different facets of the task itself, not in isolation, the vocabulary, grammatical constructs, text types, capitalization, punctuation, and social norms required to carry out each task will be learned, exercised, and evaluated. Strategic maturity is also closely related to language abilities and, if they wish to use language from the outset for genuine conversation, students need to find how to compensate for low skills in the early stages of learning. In the language use strategies in the Strategies portion, this aspect is included.

Significantly, using mother tongue in oral and written communication made a great impression on the learning of a child's cognitive capacity. This claim has been supported by the Republic Act No. 10157 also known as the Mother Tongue- Based- Multilingual Education (MTB-MLE) method which aimed "To develop appropriate cognitive and reasoning skills enabling children to operate equally in different languages- starting in the mother tongue with transition to Filipino and then English and to preserve the Philippine cultural treasure as well."

According to the Department of Education's 2012 Bilingual Education Proposal, Filipino students must be proficient in at least two languages upon graduation from high school: Filipino (Tagalog) and English (Department of Education, 2013). There will also be hundreds of thousands more who speak a local language and a major regional language fluently. Take a person living on Leyte Island, for example: this person may speak Bisaya at home, use WarayWaray in the wider society, get Filipino through school and mass media, and learn English from third grade onwards as well. During the course of his or her day, the speaker can turn between any of the four languages, depending on the context of the situation. All in all, the Filipinos do not hold on to their mother tongue in the same manner as Westerners do. In the tempo of Filipinos to switch from a mother tongue to a local or national language and back, this notion is embodied.

Thompson also examined teachers and students and observed that respondents found it difficult to converse in pure Tagalog or pure English sentences, resulting in poor comprehension and lack of understanding of the various disciplines [40]. They then resorted to combining the two languages in order to communicate their messages, to promote understanding and to encourage understanding. Abad forwarded the same line of conclusion when she discussed that code-switching helps students to express themselves within the classroom [1]. Code-switching aids in the victorious negotiation of the context of complex texts coded in English and provides direct feedback to learners; creates a low-anxiety classroom environment conducive to learning; and holds students in a classroom where lessons are of a highly technical sort.

In addition, owing to the large cultural variations between the English language and the Philippine national language, Filipino and other native Philippine languages, which are the 
mother tongues of the students, not all Filipino learners are able to learn English through an English-only-policy (EOP) mode of instruction. There is also a wide difference between the mother tongue of a Filipino student and the English language, which is a foreign language for Filipino students and the learning process which the comprehension skills is one to be considered the most.

In the Tanauan School of Craftsmanship and Home Industries, Tanauan, Leyte, in spite of the strategic interventions done by the English teachers to improve the comprehension level of the students, the comprehension still appears to be below $75 \%$ as seen in the Mean-MPS result of $56.23 \%$ for Grade 7 students for school year 2015-2016 and increased to $61.45 \%$ for school year 2016-2017 and lessened to $58.91 \%$ for the school year 2017-2018. Hence, the situation needs preferential attention to address the problem.

To address the issue, the researcher attempts to find out if a classroom that uses Code- Switching as a language teaching strategy anchored to grammar- translation method achieves higher learning levels compared to English-only-policy teaching.

\section{Statement of the Problem}

This study aimed to investigate the effectiveness of CodeSwitching as a Language Teaching Strategy anchored on the Grammar- Translation Method for Comprehension Enhancement to the Grade 7 students of Tanauan School of Craftsmanship and Home Industries, Tanauan, Leyte during the School Year 2018-2019.

Specifically, this research sought answers to the following questions:

1. What is the profile of the respondents in terms of the following: Age, Gender, Type of School and Spoken Language (s)?

2. What is the level of comprehension of the respondents in the control and experimental groups in terms of their pre-test mean scores in Teaching Capitalization, Teaching Punctuation, Teaching Grammar, Teaching Sentence Structure, and Teaching Word Usage?

3. What is the level of comprehension of the respondents in the control and experimental groups in terms of their post-test mean scores in Teaching Capitalization, Teaching Punctuation, Teaching Grammar, Teaching Sentence Structure and Teaching Word Usage?

4. Is there a significant difference in the level of comprehension of the respondents in the control group in terms of pre-test and post-test mean scores?

5. Is there a significant difference in the level of comprehension of the respondents in the experimental group in terms of pre-test and post-test mean scores?

6. What are the teaching- learning experiences of teachers in using code- switching as a language teaching strategy anchored on the grammar- translation method?

Clearly, there are a number of matters that need careful examination regarding the effectiveness of code- switching as a language teaching strategy anchored on grammartranslation method for comprehension enhancement of Grade 7 students at the Tanauan School of Craftsmanship and Home Industries, Tanauan, Leyte.

\section{Null Hypotheses}

The following null hypotheses were tested:

1. There is no significant difference in the level of comprehension of the respondents in the control group in terms of pre-test and post-test mean scores.

2. There is no significant difference in the level of comprehension of the respondents in the experimental group in terms of pre-test and post-test mean scores.

\section{Theoretical Framework}

Two theoretical perspectives have dominated the study of code- switching as a language teaching strategy: Language Acquisition Theory and Language Comprehension Development. Various ideas were drawn to direct the study; theories of language learning are among them. Where there is imitation theory, which asserts that by listening to the speech around them and reproducing what they understand, children learn language. This hypothesis elaborates that the learning of language consists of memorizing some language's vocabulary and phrases. The definition is that language processing is the method of learning to mimic voice. Children must hear and either repeat or copy certain words used by other speakers.

Thorndike explored that when a child spontaneously creates a wide range of sounds, some of these sounds mimic words and are reinforced by the atmosphere of the child [41]. The infant then learns to use the awarded sounds to produce identical outcomes in similar circumstances. Thorndike considered the probability of a child being unconsciously pleased with making a sound close to that which rings in the ears of memory and sense. This was illustrated by the compilation of data that the language they learned was used by most learners in class. That is, students were able to mimic their teacher's words that they learned around in the classroom.

The theory's advocates may reason for this by arguing that language is hard to learn and so the first attempt by an infant to imitate different vocabulary or expression forms and the structures were not flawless. This is not shocking, because learning to talk takes a great deal of expression and practice, as learning to speak is like learning to communicate.

By citing cases of children learning from parents, however, Thorndike argued that, sometimes, they would mispronounce terms and use grammar that they have never learned from adults. Statements such as, "My mother bought this toy for me," are an example. In lieu of 'bought', parents do not use the term' bought ' [41].

On the other hand, the growth of language understanding may be linked to the philosophy of Vygotsky in the Philippine educational sense, as the syllabus notes that students can learn and understand spoken English [42]. Students need to partake in oral communications to do so, such as couple talks or group work. The principle of Vygotsky notes that the language and understanding abilities of learners evolve within the proximal growth zone of the learner (ZPD) [42]. The proximal growth zone of a learner refers to the zone where development can occur. The proximal growth zone of a learner refers to the zone where 
development can occur. Two children whose mental age is eight are an example of Vygotsky. Both children were offered a more complicated problem that they could individually solve. However, one of the children could solve challenges intended for the age of twelve with help, while the other child could only solve challenges intended for the age of nine. This illustrates the ZPD; "the discrepancy between the actual mental age of a child and the level he reaches in solving assistance problems"[42]. In addition, the proximal development zone of a student is necessary to consider, because "learners can only benefit from [scaffolding] if they are in the ZPD." This ensures that learners can grow their language learning primarily in the language classroom and comprehension if they are learning at a stage above their current level of knowledge with the support of other learners or teachers. In the English classroom, for example, it is important that the teacher considers the progress of the particular student and gives the students assignments accordingly, because if the tasks are too straightforward, the students will not improve their language learning, the same goes if the issues are too hard for the students to understand with assistance.

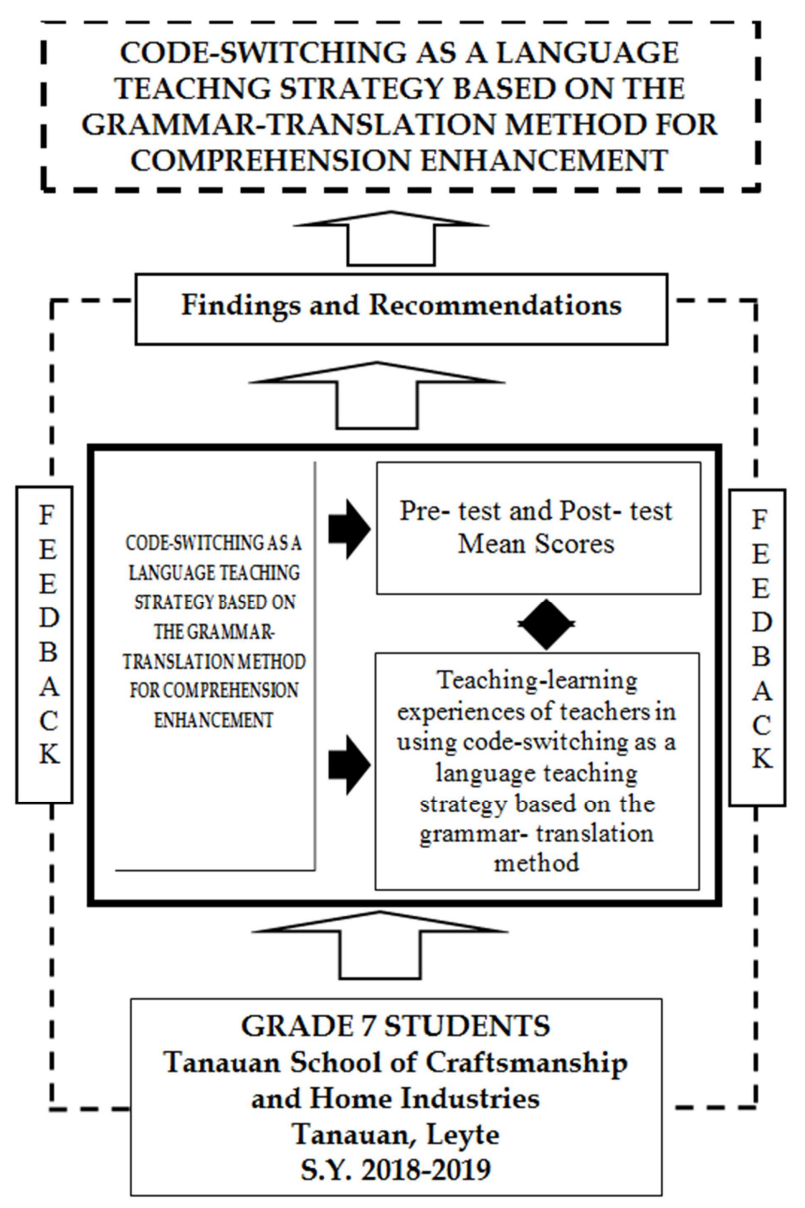

Figure 1. Conceptual Framework of the Study.

Therefore, in this review, the researcher refers to the communicative skills based on speech and understanding that are listed in the syllabus for English secondary school when addressing language comprehension progress. In addition, the emphasis is on Vygotsky's theory of language learning since the language learning being examined is related to a sociocultural perspective and thus also to the proximal growth zone of learners.

\section{Conceptual Framework}

The box at the left represents code-switching as a language teaching strategy based on the grammar-translation method for comprehension enhancement.

The same box is connected to two smaller boxes to the right representing student-respondents' level of comprehension in the control and experimental groups in the pre-test and post-test mean scores and the teaching-learning experiences of teachers in using code-switching as a language teaching strategy based on the grammar-translation method using two-way arrows indicating that correlational analysis has been performed between the variables contained in each box.

This big frame is connected upward to a smaller box representing the findings and recommendations.

The smaller box representing the findings and recommendations is also connected downward to the bottom frame which indicates the feedback mechanism of the study, then, to the next upper box representing the goal of the study which is the effectiveness of code-switching language teaching strategy based on the grammar-translation method for comprehension enhancement.

Significance of the Study

The result of the study is beneficial to the following:

Teachers of English. The outcome of the study leads English teachers to learn about how they can serve their students as models by adhering to the use of English. The outcome of this analysis should be used by teachers to be attentive to the desires of students who are the key variables to be addressed in developing worthwhile practices of contact and learning.

Students. The result of this study will benefit learners to become motivated and resolute to be more enthusiastic in understanding the use of the English language in and out of the classroom setting and expand their holistic being.

Parents and Administrators. Parents and managers will value the use of English from the results of this research and accept the language's demands and challenges. The outcome of this analysis would enable them to recognize the problems of code-switching and reduce their antagonistic interpretation of the language. Via the results of this report, the group will expand its supportive support to enlighten their children about the advantages they might get by studying the English language.

Content Field Educators. This research would assist teachers or educators of every learning organization to change or establish new language policies about the role of code-switching in the classroom.

Future Researchers. Future teaching researchers will use the results of this study to connect other future research and use it as a guide for their related scholarly research to other similar studies.

Scope and Delimitations of the Study 
This study investigated the effectiveness of code-switching as a language teaching strategy based on the grammartranslation method for comprehension enhancement.

This involved 60 Grade-7 students and two English teachers of Tanauan School of Craftsmanship and Home Industries, Tanauan, Leyte. The Grade 7-students were chosen because of the transition of the learning process from primary to secondary. The basic language competencies included in this study were limited to capitalization, punctuation, grammar, sentence structure, and word usage.

The 60 students were divided into a comparable group of 15; each group matched using grades during the first and second quarter. The control group was exposed to the English-only-policy approach, while the experimental group was exposed to the code- switching as a language teaching strategy.

A teacher-made test was used as the main data gathering tool to gather the data needed for this study. This study was conducted during the school year 2018-2019.

Definition of Terms

The following terms are given conceptual as well as operational definitions to offer better understanding to the readers:

Capitalization. This refers to writing a word with its first letter as a capital letter (uppercase letter) and the remaining letters in lower case, in writing systems with a case distinction. The term also may refer to the choice of the casing applied to text.

Code-Switching. Conceptually, this refers to a multifaceted, experienced dialectal scheme used by multilingual speakers to express significant communal implications above and beyond the referential content of an expression [13]. Operationally, this term refers to the co-existence of diverse language variations within a lone setting or dialogue to better converse with speakers and to assist dissimilar communicative commitments in listening and speaking.

Comprehension. Conceptually, this term refers to the active process and the reader must interact and be engaged with the text for it to work well [21]. Operationally, this refers to the capacity of the mind to perceive and understand the meanings conversed through oral or written communication.

Control Group. Operationally, this term refers to a baseline group that receives no treatment or a neutral treatment. To assess treatment effects, the experimenter compares results in the control group.

Experimental Group. Operationally, this term refers to the group in an experiment that receives the variable being tested.

Grammar. Operationally, the term refers also to the study of such rules and this field includes phonology, morphology, and syntax, often complemented by phonetics, semantics and pragmatics.

Grammar-Translation Method. Operationally, this term refers to a method of second language instruction based mostly on the translation of passages from the native language into the target language.

Punctuation. Conceptually, the term refers to one of the paralinguistic graphological properties of a text which helps the same way as suprasegmental features. Operationally, the term refers to the use of spacing, conventional signs and certain typographical devices as aids to the understanding and correct reading of written text whether read silently or aloud.

Sentence Structure. Conceptually, this term refers to the linguistically demanding task in which students must use syntactic knowledge to generate text by combining words into groups. Operationally, this term is the way a sentence is arranged, grammatically. The sentence structure of your writing includes where the noun and verb fall within an individual sentence.

Word Usage. This refers to how a word, phrase, or concept is used in a language. Lexicographers gather samples of written instances where a word is used and analyze them to determine patterns of regional or social usage as well as meaning.

\section{Review of Related Literature and Studies}

\subsection{Related Literature}

The discussions in this section are taken from the ideas of authors of books, journals and other reference materials that deal with code-switching as a language teaching strategy based on the grammar-translation method.

Based on the comprehensive body of investigation on code-switching, it is extremely granted that code is the overall authority term for languages, dialects, styles and registers. As Wardaugh (2010) quantifies, code is "the specific dialect or language that a human being chooses to use on any occurrence, a scheme used for communication between two or more parties" [43].

Nilep (2006) on his paper 'Code Switching in SocioCultural Linguistics' displays that over 1,800 articles were distributed on the subject of code- switching in each division of linguistics, practically [33].

Another projecting description of code-switching is articulated by Myers- Scotton who asserts that code switches are linguistic varieties which are "consultations of private Rights and Obligations (RO) relative to those of other participants in a talk exchange" $[30,31]$. Her explanation of the moralities and responsibilities lies in considering the outlooks, present condition, and feelings of the audience member. Though, on form that such understanding is realized, the speaker may start his/her substituting of the code. In the final saying, Mackey pointed out that it is vital to take into account that code-switching is seen as a functionally stirred development rather than an accidental one [27].

Code-switching can be categorized from both a collective and a syntactic viewpoint. One of the leading sociolinguistic readings of code-switching by Blom and Gumperz acknowledged two basic types, namely metaphorical and situational code-switching, although this classification was later widened to include a third type, namely conversational 
code-switching [6]. As pointed out by Hamers and Blanc (2000) the term code-switching in this perspective is used to signify a bilingual communicative approach consisting of another use of two languages in the same discussion, even within the same statement/judgment [17]. In this piece, a division is made between situational and metaphorical codeswitching. Following this, a narrative of code-switching as a conversational plan is specified. Lastly, a structural peculiarity is made between intra, inter- and extra-sentential code-switching.

Wardaugh illustrated situational code-switching happens when the language used deviates according to the conditions in which the conversant finds themselves: they communicate one language in one state and another in a diverse one [43].

On the other hand, Downes presents the idea of 'functional specialization' and the presence of 'spheres of language' [9]. This is in line with his disputation that diversities have different usages and when a speaker takes a specific code, they can be ratifying a purpose to redefine the status quo in which they are sharing. Nilep (2006) assumes Bloms and Gumperz affirmation that communal proceedings, defined in terms of contributors, situation, and theme, confine the collection of philological variables $[33,6]$.

Moreover, Bautista is one of those individuals who thought that forsaking the natural language use may seem unwanted in the development of learning the native language [4]. $\mathrm{He}$ believed that since the learners' views and concepts are already established in the chief language, doing away with students' first languages may hamper their process of conceptualization which is principally based on their native language [4].

There are certain explanations why scholars are in contradiction of the usage of the mother tongue in the lecture room. In Harmer's study 'The Practice of English Language Teaching' stated that one intention they place on the board is that the use of the vernacular makes the classroom appear more truthful and reliable. Another reason is that in a multilingual lesson where there may be dissimilar first languages, it looks as if quite unbearable to take into account all of them [18].

The usage of the native language in the schoolroom aids diverse purposes. Cook (2001) campaigns the use of the native language in the classroom [8]. He considers that the use of the native language in the class cannot be all inquisitive and disadvantageous, but it has some optimistic ideas. He asserts that language rules can be elucidated through by means of the native language because meaning can be taken more visibly [8]. The classroom can be accomplished more certainly.

Similarly, Wardaugh says that the code we want to use for a single event defines how we want people to see us. The change to a diverse code will then be impacted by the expected conversational purpose [43]. He also claims that any form of structure that reciters operate during conversation can be referred to by the word code, which is distinct from words such as language, dialect, style, vernacular standard language, pidgin, and Creole that are inclined to hold feelings. Therefore, it is imperative not only to receive sheltered portions of a target language (L2) while learning a language, but to be able to use those portions in parallel when speaking, reading, writing, or listening in your second language [43]. The study of code-switching from a sociolinguistic point of view goes deeper than the presence of code-switching to the objectives and intentions behind its use.

In Simon's study 'Towards a New Understanding of CodeSwitching in the Foreign Language Classroom' he emphasized that students use their native language to converse between one another and by doing so, they get a comprehensible reply if the other learners have the same or a different awareness of the established information [39]. All of this is done so that the learners can convey meaning in a shortened way and, thus, help own learning development [39].

A great body of work has been dedicated to examining why speakers tend to use a definite code, what reasons cause shifts from one code to another, and why speakers in many cases desire to use a new industrialized code from two other codes by code-switching back and forth between the two. Grosjean (2012) on the details why people code-switch: it is because definite impressions or concepts can simply be better conveyed and assumed in the other language; speakers may need also to fill a linguistic opening for a manifestation or an expression [13].

Justly, proficiency of one diversity of a language, be it a vernacular, list, or style, seems to be an extremely infrequent occurrence. Numerous scholars, such as Myers- Scotton and Auer, Poplack and Thompson have directed discerning research on the theme of code-switching as a policy engaged by multilingual speakers whose understanding skills are high in both languages involved [30, 2, 35, 42].

Finlayson and Myers-Scotton put forth that students whose grasp was low, deliberated code-switching in their English as a Foreign Language (EFL) classes as supportive towards acquiring better comprehension as well as giving classroom measures [11]. Kachru (2009) further maintains that there is, by no means, any motive for branding diversity as far as it is subjugated for real language teaching [19]. Stigmatization of code-switching, according to Macaro (2001), is credited to undesirable features such as shortage of education, illiteracy, or lack of comprehension in one language or both [25]. On the other side, Bernardo (2005) found an inconsistent connection between code-switching and the mark of contact to the target language: when exposure to the target language augmented, code-switching reduced [5]. Nevertheless, he recognized that the compensations of using code-switching in the classroom overshadowed the shortcomings.

Henceforth, due to this attachment among people who are bilingual or multilingual, there is a necessity to link with one another outcome, in several cases, in code-switching, which was the range of conversation in this study.

\subsection{Related Studies}

Among all the research studies reviewed by the researcher, the following were found to be of value to the present study; hence they were summarized here. 
One of the subjects of sociolinguistics is most interested in the study of code-switching. There are some previous studies related to the use of code-switching that mainly contribute to the development of this study.

Myuthusamy stressed out that code-switching happens in online interaction to serve addressee specification, reiteration, message qualification, clarification, emphasis, checking, indicating emotions, availability, principle of economy and free switching functions [32]. This study provided insights on the code-switching phenomenon in Computer-Mediated Communication (CMC).

Lin studied the effects of code-switching in the student's vocabulary learning. Findings revealed that the amount of cognitive processing code made by students is increased by code-switching [24]. The researcher stressed out that a greater reasoning exertion is prerequisite to route arguments when there is both a clarification in the learners' L2 and a conversion into the learners' L1, which could mean that the learners will learn first-hand terminology more methodically [24]. Although the findings did not display that codeswitching was real in learning new expressions, it did show that code-switching did not disturb terminology learning in an adverse mode.

In addition to these aforementioned references, some linguistic studies have focused on the use of CS in the learning process. Finlayson and Calteaux randomly selected 45 diploma students as respondents and distributed a survey questionnaire which focused on the students' attitudes, usage, and opinion toward code-switching in the classroom [11].

Leyew's study 'Code-Switching: Amharic-English. Journal of African Cultural Studies' showed that most ESL learners have positive attitudes toward code-switching and believe that this strategy helps their understanding of the target language [22]. In addition to the different results throughout academia regarding code-switching strategy and process costs, further studies pointed out that language comprehension in bilingual studies have shown cost-free switching when reading words silently, in relation to lexical processing and when reading the words out loud, such as in production [22]. However, this leads to the question of the differences between language production and language comprehension in the bilingual speaker: for instance, are both lexicons accessed at the same time while in a code-switching environment? Are the languages accessed via competition in the brain, or are they activated simultaneously?

Later studies of Lin (2013) and Cook (2008) showed that code-switching develops close relationships between students and their teachers making the classroom interaction more natural and easier [24, 8].

Gulzar (2004) also made a point that code-switching strategy can be utilized in formal situations to make teaching more effective. It helps in translating or explaining concepts from a teacher's explanation about what is said in the curriculum or another academic text [14]. This strategy leads teaching more efficiently since the students can understand faster and more thoroughly, making teacher's code-switching an important tool for explanations and instructions.
Code-switching also conveys emotional purposes that aid for voicing feelings. For example, code-switching is used by the trainer to shape harmony and close relationships with the learners, or to generate a helpful language setting in the classroom. Li appealed that code-switching supports students to appreciate their education due to their capability to understand the instructors' idea [23]. Accepting what is being said establishes mental support for the students, permits them to sense less tense and apprehensive, and makes target language more relaxed to learn. At that state, students can center and take part in classroom events in a more effective way.

Cohen and Macaro who examined the student's perception level of English proficiency in secondary schools noted that factors like attitude, anxiety, class activity, motivation and learning resources were influencing English learning [7]. Results revealed that both factors have positive correlations which perceive English proficiency [7].

Code-switching can be found everywhere and, thus, a common phenomenon. Some studies on code-switching show that code-switching has its types and reasons. Poplack propose three types of code-switching in grammatical classification, namely tag-switching, intra-sentential switching, and inter-sentential switching, and two kinds of code-switching in contextual classification: they are situational code-switching and metaphorical code-switching [35].

In contrast, Guthrie reported that there was no correlation between the student's different levels of comprehension and their use of code switching [16]. In fact, advanced learners and competent bilinguals have been reported to employ codeswitching similarly according to a study of Auerbach [3]. Finlayson and Slabbert reported that students with low comprehension considered this strategy as helpful in gaining better comprehension and giving classroom procedures in their English as a Foreign Language (EFL) classes [10].

In addition, in their study entitled 'Code-Switching Lessons: Grammar Techniques for Linguistically Diverse Authors,' Garcia and Wei (2013) suggested that codeswitching lessons provide a tailored, efficient solution to traditional literacy teaching [12]. A research-based approach is offered by code-switching lessons: contrastive analysis and code-switching. The instructor builds on the linguistic insights of contrasting research that both languages are patterned and that dialects are routinely contrasting with each other. Therefore, she urged students to equate the grammatical trends of home speech with the grammatical trends of school speech [12]. Code-switching courses bring logical reasoning (analysis and synthesis) techniques to the discovery of grammar. Code-switching often helps learners to select their language to suit the world as a child, then learns to switch code between the home language and the school language. Teachers add another linguistic code, Standard English, to the child's linguistic toolbox.

Grosjean explored the reasons why people use codeswitching: it is because the other language can actually help convey and comprehend those ideas or notions; speakers 
might also need to fill a linguistic void with a phrase or a phrase [13].

Further, Kachru asserted that there was, by no means, any reason for stigmatizing a variety as far as it was exploited for effective language teaching [19]. Macaro explained that stigmatization of code-switching was attributed to negative aspects such as lack of education, illiteracy, or lack of comprehension in one language or both [25].

As to the studies made by Gumperz 'Discourse Strategies', the central dispute for escaping code-switching is that the learners' miscue on ideas in the aimed language and are destitute of honest L2 collaboration [15]. In clusters with more than one L1, the educators must preferably be able to relay to all L1s. Since this is impossible, Matila believed that code-switching should be ducked, and the target language be employed dependably in its place [28]. One scheme that dodges the L1 is the teaching technique Communicative Language Teaching, which since the 1970s has been one of the most accepted training approaches in the sphere [36]. It centers on target linguistic messages rather than educating the linguistic systems of a language. Through contribution in communicative events the L2 students are using the target language and the persistence is to use the target language in order to obtain it. Subsequently, Qing further notifies codeswitching must be kept to a slightest in the L2 classroom [36]

Olmo-Castillo explained that the main argument for avoiding code-switching is that the students miss out on input in the target language and are deprived of genuine L2 interaction [34]. In groups with more than one L1, the teachers should ideally be able to relate to all L1s. Since this is not possible, code-switching should be avoided, and the target language be used consistently instead [34].

Wardaugh identified several aspects relating to the significance of conversational code-switching in a multilingual setting, namely: that a presenter can access different characteristics and accommodate others, meet someone else halfway, and launch collective ground and display elasticity and honesty [43].

In general, code-switching in casual situations is not a critical concern, nevertheless scholars continue to demonstrate and verify whether it is really permitted to codeswitch in the classroom especially in English classes. Some studies attested that bilingualism along teaching may accelerate the understanding of a thought. Code-switching could accomplish to lower the emotional filter, and this consequently recognized relationship and shaped an atmosphere of familiarity, thus, letting any student to vigorously take part in the classroom conversation. Reserves would be reduced, and learning comes in [1].

Maehlum's "Code switching in Hemnesberget-myth or reality?" Journal of Pragmatics' emphasized the incidence and design of code-switching also fluctuates in view of policy conditions of the school [26]. In some schools, the use of a language other than English is disciplinary. It is believed that relative to learners who are only exposed to any form of English at school, learners who use English in and outside the classroom as well as at home are less likely to use code- switching [26]. Therefore, the frequency of CS for teachers is likely to correspond with the groups of learners in the classroom, the school's political situation, and other circumstantial problems relevant to the classroom.

Conversely, the use of the vernacular in the classroom aids different functions. Muysken promotes the use of the first language in the classroom [29]. However, on condition that such understanding is achieved, the speaker may initiate his/ her switching of the code. Mackey claimed in the final statement that it is necessary to take into account that code switching is seen as a technically motivated rather than a random operation [27].

Since there is no agreement among scholars concerning code-switching in the foreign language classroom, Schedl and Wright agreed it may be more satisfactory to entitle that code-switching should be permitted whenever needed with some students in definite circumstances [38]. Additionally, code-switching should be stared as a cautious tactic engaged by the educators, which has some constructive and enabling purposes accepted by both the educators and students, such as clarifying grammar and new terminology, dipping students' pressure, expounding orders, and creating a connection with students.

Moreover, students use their mother tongue to converse amongst one another and, by doing so, they get a comprehensible reaction if the other students have the same or a dissimilar insight of the conventional data. All of this is prepared so that the students can exchange denotation in a shortened method and, thus, aid their own learning practice [37].

Hence, due to this affiliation among people who are bilingual or multilingual, there was a need to correlate results, in many cases, to code- switching which was the scope of discussion in this study.

\section{Methodology}

This chapter presents the research design, instrumentation, validation of the instruments, sampling procedure, data gathering procedure and statistical treatment of data.

\subsection{Research Design}

The study aimed to investigate the effectiveness of codeswitching as a language teaching strategy based on the grammar-translation method for comprehension enhancement.

This study adopted a mixed-method research using the triangulation method specifically the sequential explanatory design. A mixed-method research integrates qualitative and quantitative approaches of collecting data. It approaches a problem expansively from more than one point of view by mixing the qualitative and quantitative data together in order to draw close decisions to the subjects being studied. Additionally, in social science, triangulation is defined as the mixing of data so that diverse perspectives or stances cast light upon the subject. The mixing of data types known as triangulation is often believed to help in confirming the assertions that might ascend from a preliminary experimental 
study. The mixing of methods, e.g. mixing the use of survey data with interviews, is a more profound form of triangulation.

Additionally, this study also employed the trueexperimental method of research. According to Shuttleworth (2018), for many true-experimental designs, pre-test and post-test designs are the preferred method to compare participant groups and measure the degree of change occurring as a result of treatments or interventions. One group is given the treatment and the results are gathered at the end. The control group receives no treatment, over the same period of time, but undergoes exactly the same tests. Specifically, it adopted pre-test and post-test group design as shown in Figure 2.

\begin{tabular}{|l|l|l|l|}
\hline R1 & Q1 & & Q2 \\
\hline R2 & Q3 & X & Q4 \\
\hline
\end{tabular}

Figure 2. Pretest- posttest design.

Where:

$\mathrm{R}=$ Random assignment

$\mathrm{Q} 1=$ Control pre-test

Q3=Experimental pre-test

$\mathrm{Q} 2=$ Control post-test

$\mathrm{Q} 4=$ Experimental post-test

$\mathrm{X}=$ Treatment (Code-Switching)

The design requires two groups of equivalent standing in terms of a criterion measure, e.g., achievement of mental ability. The first group is designated as the control group while the second group is the experimental group. Both groups are given the same pre-test. The control group is not subjected to a treatment while the experimental group is given the treatment factor. After the experimental period, both groups are given the same post-test (Padua, 1995).

As stated earlier, two groups are under study, one is the control group exposed to the English-only-policy method while the experimental group exposed to the code-switching language teaching strategy anchored on the grammartranslation method for comprehension enhancement. The lesson covers the language competencies found in the Grade 7 curriculum guide: capitalization, punctuation, grammar, sentence structure and word usage.

A 50-item test was administered to the subjects of the study during the pre-test and post-test. The data generated were statistically treated using the mean, standard deviation, and t-tests of dependent and independent samples.

On the other hand, through teacher interview and classroom assessment, the qualitative knowledge gathered in this analysis was collected. Holistic, descriptive, and natural data are the subject of qualitative analysis methods. It compels arguments on how items work in various contexts. The entire statement concerning qualitative analysis is summed up in the Schendl \& Wright (2011) definition, which is as follows:

Implications were drawn from the findings of the study in investigating the effectiveness of code-switching as a language teaching strategy anchored on the grammar- translation method for comprehension enhancement as well as to make suggestions for improvement or in addressing identified factors that hinder its effectiveness.

\subsection{Instrumentation}

This study used a teacher-made test, semi-structured interview and classroom observation as its main data collection tools which were augmented by the application of the analysis of the said data collection instrument and method as discussed below:

Achievement Test. The questionnaire as a primary tool in data gathering was a teacher-made test based on the language competencies covered in this research. The test was prepared by the researcher to determine the pre and post-test mean scores of the two groups namely: control group and experimental group. It was a multiple-choice type of test that was patterned after the Philippine Secondary Competencies which used the Bloom's Taxonomy of Objectives.

The researcher administered two sets of test to the participants upon getting the approval. Set A was a Pre-test on language learning competencies. The second set of test was Set B, a Post-Test, which contained the same questions in set A, parallel in nature, but not identical, to avoid bias and familiarization of the test items. This teacher-made test was intended to gather the needed data directly from the Grade-7 students of Tanauan School of Craftsmanship and Home Industries. Hence, the whole instrument was made up of three parts.

Part I pertained to the personal background of the respondents in terms of their age, gender, type of school and spoken language (s).

Part II was a 50-item teacher-made test intended to measure the effectiveness of code-switching as a language teaching strategy based on the grammar-translation method for comprehension enhancement. The level of comprehension was based on the Form 138-A scoring system by the Department of Education stated below:

Score Level of Proficiency

41-50 Outstanding

31-40 Very Satisfactory

21-30 Satisfactory

11-20 Fairly Satisfactory

0-10 Did Not Meet Expectations

Teacher Interview. Interviews are one of the main qualitative data collections; they allow researchers to acquire individual perceptions, interactions, viewpoints, and opinions. Semi-structured interviews were driven in this analysis in that the investigator used a preset series of questions and topics on which the interviewees were to answer. However, based on the flow of the conversation, the interviewer also needed further questions.

Classroom Observation. The observation of lessons in the classroom was appropriate for the qualitative part of this study as it allowed the researcher to study the phenomenon of code-switching in the classroom as it occurred. Owing the absence of video recording, notes were taken down about the physical environment of the classroom to give a clear picture 
of what was actually taking place during the lessons.

\subsection{Validation of the Instruments}

The research instrument utilized in this study was validated using two types of validation procedure: 1) try-out; and 2) expert validation.

First, the drafted pre-test and post-test by the researcher was submitted to the adviser for expert validation focusing on the very content of the instruments. After which, the test was re-drafted by integrating all the suggestions provided by the researcher's adviser in preparation for the second validation procedure, the try-out.

Second, the pre-test and post-test were tried out to the Grade-7 students of Tanauan School of Arts and Trade after securing permission from the Principal and the English teacher concerned on February 4, 2019.

To ensure the validity of the test, a 70-item test on language competencies was constructed by the researcher based on the Table of Specifications prepared by the researcher using Bloom's Taxonomy of Objectives to determine the effectiveness of code-switching as a language teaching strategy based on the grammar-translation method for comprehension enhancement.

The results of the validation became the basis of the final rephrasing, omitting, and even constructing of additional information necessary for a more reliable research output.

Out of 70 items subjected for validation, 41 were retained, 22 were revised, and seven (7) were discarded. The selection of the final 50 items was based on the results of difficulty and discrimination indices. It was the basis of the rejection, retention, and revision of the test items that were included in the final form of the achievement test used for pre and posttests. It used a table of equivalents to interpret the difficulty index (Orlando \& Orlando, 1989).

The Kudar-Richardson Coefficient was computed to determine the reliability of the teacher-constructed test. It obtained a value of 0.731 which fell \pm 0.70 to \pm 0.90 interpreted as high relationships (Downie and Health, 1984). Thus, it was reliable.

\subsection{Sampling Procedure}

The respondents of this study were 60 Grade- 7 students of Tanauan School of Craftsmanship and Home Industries enrolled during school year 2018-2019.

The Grade-7 respondents were comprised of four sections, namely: Titan (15), Enceladus (15), Io (15) and Europa (15). Each section was composed of 15 randomly selected students using the Simple Random Sampling.

As stated, Simple Random sampling, specifically the Fish Bowl Technique, was used to select the students paying attention to gender and grades. Names of the studentrespondents were written in small, rolled pieces of paper placed in a fishbowl. Later, these rolled pieces of paper were drawn, one after another, until the desired sample size was reached. A total of 15 students were selected for each section mentioned. From each stream, a class list was obtained for random sampling of the 15 students. The purpose of using random sampling was to reduce bias so each student had an equal chance of being picked in participating and also all students gained an understanding of code-switching as a language teaching strategy in the English learning process.

The number of respondents was divided into two groups and assigned to control group composed of 30 students and experimental group with 30 students to assure validity and reliability in the process.

\subsection{Data Gathering Procedure}

Right after the instruments were validated and retested, the researcher finalized the research instruments. Permission was taken first from the office of the Schools Division Superintendent in a form of letter request for the testing and administration of the research questionnaire. Then, this approval was used by the researcher to seek permission from the school principal allowing him to conduct the study.

The researcher with the permission secured from the Schools Division Superintendent and school principal involved in this study, personally distributed the assessmentquestionnaire during the English period of the students with the help of the English teachers, and retrieved them immediately. This was done to ensure $100 \%$ retrieval.

When all the copies of the assessment-questionnaire were answered by the respondents, the data gathered were checked, arranged and organized using a Microsoft Excel in order to find out the level of comprehension of the studentrespondents. Upon determining the level of comprehension of the respondents, the researcher conducted a semistructured type of interview acquiring information from the English teachers who handled the respondents.

When all the questions were answered by the teacherrespondents, the gathered data were organized and analyzed by the researcher and employed appropriate statistical tool so that desired findings and conclusions in this study came out. Any responses from the student-respondents and teacherrespondents were treated with certain degree of confidentiality by the researcher.

\subsection{Experimental Procedure}

The researcher secured a written permission from the Principal of Tanauan School of Craftsmanship and Home Industries to conduct a study. Arrangements were then made with the concerned teachers who were utilized as subjects of the study. The four (4) sections who belong to the heterogeneous group of Grade-7 students were the respondents of the study.

Each section involved 15 students with comparable average ratings during the first and second quarter in English. They were then clustered into control and experimental groups.

The first two sections were the control group exposed to the English-only-policy method of teaching and the remaining two sections were the experimental group exposed to the code-switching method. Each pair of students was 
assigned randomly using fishbowl technique on the group assignment since the pair had similar grades.

Classes were conducted during their English period from 7:30 to 9:30 a.m. for the first group and 12:45 to 2:45 p.m. for the second group. Exercises were given to the students after each lesson and the evaluation was given after the five lessons. After the experiment, a post-test was administered to the two groups and the scores were tallied, compared, computed, analyzed, and interpreted

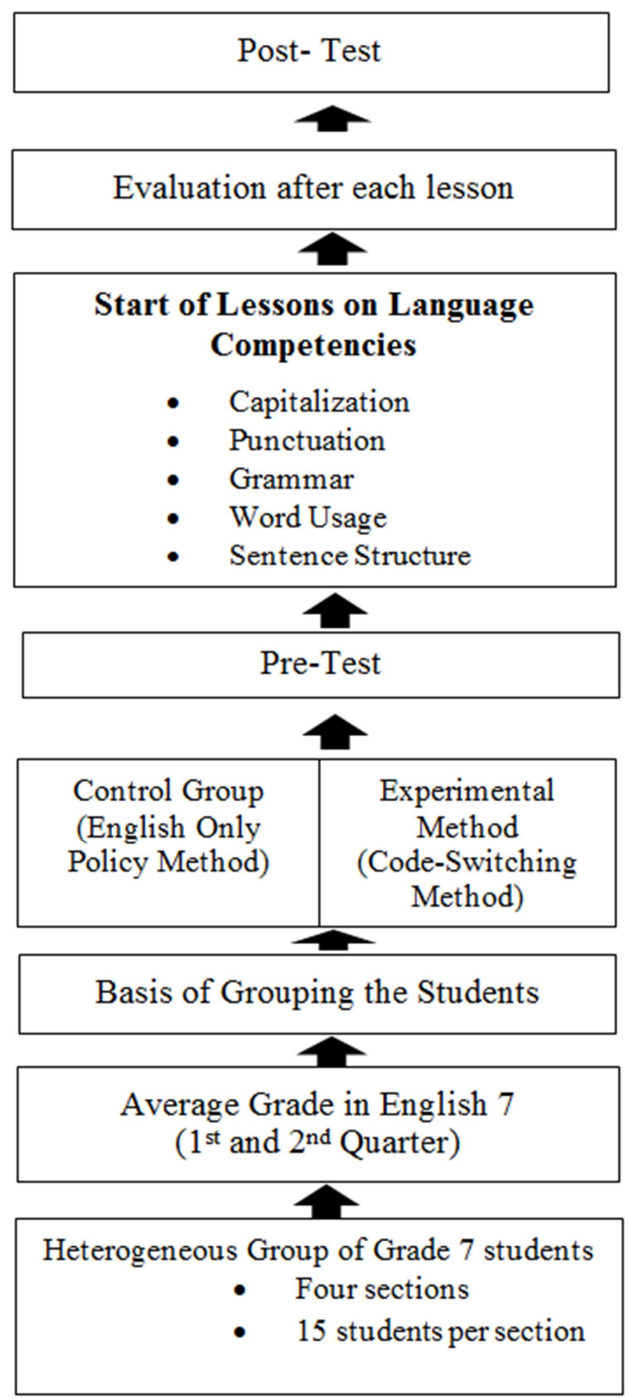

Figure 3. Flow of the experiment.

\subsection{Statistical Treatment of Data}

The data gathered through the use of the afore-cited achievement test were organized, tallied, tabulated, analyzed, and interpreted using appropriate statistical measures and procedures.

The following statistical tools were used to determine the profile of the respondents:

Frequency Count and Conversion of Percentages. These tools were used to determine the respondents' profile, student's performance toward the basic language competencies and techniques employed for comprehension enhancement.

Weighted Mean. This statistic was employed to determine the collective performance of student-respondents relative to the code-switching as a language teaching strategy based on the grammar-translation method for comprehension enhancement.

To determine the students' level of comprehension in the pre and post-tests, the mean values were computed with the following interpretations:

Scores Adjectival Description

9-10 Outstanding

7-8 Very Satisfactory

5-6 Satisfactory

3-4 Fairly Satisfactory

1-2 Did Not Meet Expectations

T-test. The data tallied based on the correct response of the treatment and control groups before and after employing this study were encoded for statistically process using the T-test for independent groups to determine the significance of the mean difference between the pre-test results/post- test results of the control group and experimental group.

The t-test for dependent group was used to determine the significance of the mean difference between the pre-test results and post-test results in the control and experimental group.

Transcription. On the other hand, the video-taped semistructured interview was transcribed accurately. By means of a deductive approach to content interpretation, the teachers' audiotaped answers to the collection of questions in the interview were qualitatively processed. The method of documenting and summarizing textual, visual, and verbal data is described as content analysis and aims to analyze and validate written data. Data developed in anthropology, sociology, and psychology were examined with qualitative material. For qualitative and quantitative purposes, content analysis has been applied. This entails counting sentences, phrases, and phrases and classifying them under various themes.

\section{Presentation, Analysis and Interpretation of Data}

This chapter presents the analysis, interpretation and findings of the study through pre-test and post-test scheme, classroom observation, and interviews of different respondents who participated in this study. Statistical indicators were used to present the data gathered which were analyzed and interpreted. The discussions of the findings of this study are presented into sections according to the order of the statement of the problems.

The discussions are supported by the tabular presentation of the statistical results.

\subsection{Pre-Test of the Control and Experimental Groups in the Lessons Covered}

A 50-item achievement test was conducted to both control 
and experimental groups as a pre-test to identify the achievement. The lessons covered were teaching capitalization, punctuation, grammar, sentence structure and word usage.

A duration of four (4) weeks was given to investigate the effectiveness of code-switching as a language teaching strategy based on the grammar-translation method for comprehension enhancement compared to the English-onlypolicy method.

A series of evaluation was provided to check student's comprehension and to determine if there was really a significant difference between the pre and post-tests of the control and experimental groups.

Table 1. Pre-Test in Teaching Capitalization.

\begin{tabular}{llllll}
\hline \multirow{2}{*}{ Rating } & & \multicolumn{2}{l}{ Control } & \multicolumn{2}{l}{ Experimental } \\
\cline { 2 - 6 } & & $\mathbf{f}$ & $\mathbf{\%}$ & $\mathbf{f}$ & $\%$ \\
\hline Outstanding & $(90-100)$ & 0 & 0 & 0 & 0 \\
Very Satisfactory & $(85-89)$ & 2 & 7 & 0 & 0 \\
Satisfactory & $(80-84)$ & 19 & 63 & 17 & 57 \\
Fairly Satisfactory & $(75-79)$ & 9 & 30 & 10 & 33 \\
Did Not Meet & $(70-74)$ & 0 & 0 & 3 & 10 \\
Expectations & & 30 & 100 & 30 & 100 \\
Total & & 80.83 & & 79.33 & \\
Mean & & Fairly Satisfactory & Fairly Satisfactory \\
Qualitative & & \multicolumn{3}{l}{} \\
Description & &
\end{tabular}

It can be gleaned from the table that the control group yielded a mean score of 80.83 while the experimental group yielded a mean score of 79.33. The qualitative description of control group was good while the experimental group fell into fairly satisfactory.

These data evidently display that the two sets of students were nearly identical in their aptitude and skills at the beginning of the experiment because both share to the same degree of understanding in teaching capitalization.

Table 2. Pre-Test in Teaching Punctuation.

\begin{tabular}{llllll}
\hline \multirow{2}{*}{ Rating } & & \multicolumn{2}{c}{ Control } & \multicolumn{2}{c}{ Experimental } \\
\cline { 3 - 6 } & & f & \% & f & $\%$ \\
\hline Outstanding & $(90-100)$ & 0 & 0 & 0 & 0 \\
Very Satisfactory & $(85-89)$ & 1 & 3 & 1 & 3 \\
Satisfactory & $(80-84)$ & 13 & 43 & 9 & 30 \\
Fairly Satisfactory & $(75-79)$ & 14 & 47 & 17 & 57 \\
Did Not Meet & $(70-74)$ & 2 & 7 & 3 & 10 \\
Expectations & & 30 & 100 & 30 & 100 \\
Total & & 79.17 & & 78.33 & \\
Mean & & Fairly Satisfactory & Fairly Satisfactory \\
Qualitative & & \multicolumn{4}{l}{} \\
Description & &
\end{tabular}

As shown in Table 2, the control group yielded a mean score of 79.17 while the experimental group had a mean score of 78.33 . In the control group, 1 or $3 \%$ received a very satisfactory rating, 13 or $43 \%$ fell into satisfactory rating and 14 or $47 \%$ of the students got a fairly satisfactory rating.

On the other hand, in the experimental group, 1 or $3 \%$ got a very satisfactory rating, 9 or $30 \%$ received satisfactory, and 17 or $57 \%$ was in the fairly satisfactory level of comprehension.
Both groups had a qualitative description of fairly satisfactory. It implies that the students had a common understanding of the topic.

Table 3. Pre-Test in Teaching Grammar.

\begin{tabular}{llllll}
\hline \multirow{2}{*}{ Rating } & & \multicolumn{2}{c}{ Control } & \multicolumn{2}{c}{ Experimental } \\
\cline { 3 - 6 } & & f & \% & f & $\%$ \\
\hline Outstanding & $(90-100)$ & 0 & 0 & 0 & 0 \\
Very Satisfactory & $(85-89)$ & 0 & 0 & 0 & 0 \\
Satisfactory & $(80-84)$ & 14 & 47 & 13 & 43 \\
Fairly Satisfactory & $(75-79)$ & 9 & 30 & 11 & 37 \\
Did Not Meet & $(70-74)$ & 7 & 23 & 6 & 20 \\
Expectations & & 30 & 100 & 30 & 100 \\
Total & & 78.17 & & 78.17 & \\
Mean & & Fairly Satisfactory & Fairly Satisfactory \\
Qualitative & & \multicolumn{4}{l}{} \\
Description & &
\end{tabular}

These results denote that the two groups of students are equal in their grammar skills as both of the groups have the same level of comprehension.

Table 4. Pre-Test in Teaching Sentence Structure.

\begin{tabular}{llllll}
\hline \multirow{2}{*}{ Rating } & & \multicolumn{2}{c}{ Control } & \multicolumn{2}{c}{ Experimental } \\
\cline { 3 - 6 } & & f & \% & f & $\%$ \\
\hline Outstanding & $(90-100)$ & 0 & 0 & 0 & 0 \\
Very Satisfactory & $(85-89)$ & 0 & 0 & 1 & 3 \\
Satisfactory & $(80-84)$ & 15 & 50 & 13 & 43 \\
Fairly Satisfactory & $(75-79)$ & 9 & 30 & 9 & 30 \\
Did Not Meet & $(70-74)$ & 6 & 20 & 7 & 24 \\
Expectations & & 30 & 100 & 30 & 100 \\
Total & & 78.50 & & 78.33 & \\
Mean & & Fairly Satisfactory & Fairly Satisfactory \\
Qualitative & & \multicolumn{5}{l}{} \\
Description & &
\end{tabular}

Table 5. Pre-Test in Teaching Word Usage.

\begin{tabular}{llllll}
\hline \multirow{2}{*}{ Rating } & & \multicolumn{2}{c}{ Control } & \multicolumn{2}{c}{ Experimental } \\
\cline { 3 - 6 } & & F & \% & f & $\%$ \\
\hline Outstanding & $(90-100)$ & 0 & 0 & 0 & 0 \\
Very Satisfactory & $(85-89)$ & 2 & 7 & 1 & 3 \\
Satisfactory & $(80-84)$ & 18 & 60 & 17 & 57 \\
Fairly Satisfactory & $(75-79)$ & 7 & 23 & 10 & 33 \\
Did Not Meet & $(70-74)$ & 3 & 10 & 2 & 7 \\
Expectations & & 30 & 100 & 30 & 100 \\
Total & & 80.17 & & 79.83 & \\
Mean & & Satisfactory & Fairly Satisfactory \\
Qualitative Description & & \multicolumn{5}{c}{} \\
\hline
\end{tabular}

It can be gleaned from the table that the control group yielded a mean score of 78.50 while the experimental group yielded a mean score of 78.33. The qualitative description of both groups was fairly satisfactory. In the control group, 15 or $50 \%$ of the students received a satisfactory rating, while 9 or $30 \%$ fell into the fairly satisfactory rating. Conversely, in the experimental group, there was one (1) or 3\% who got a very satisfactory rating, 13 or $43 \%$ got a satisfactory rating, and nine (9) or $30 \%$ was in the fairly satisfactory rating. These results imply that the two groups of students are equal in their grammar skills as both of the groups have the same level of comprehension.

As stated, the control group garnered a mean score of 
80.17, while the experimental group gathered 79.83 .

As gleaned, in the control group 18 or $60 \%$ of the students garnered in the satisfactory level, and seven (7) or $23 \%$ fell into the fairly satisfactory level. Meanwhile, in the experimental group, 17 or $57 \%$ of the students got a satisfactory rating, and 10 or $33 \%$ got a fairly satisfactory rating The qualitative description of control group is satisfactory and on the other hand, experimental falls into fairly satisfactory.

Table 6. $t$-Tests on the Comparison between the Control and Experimental Groups on the Pre-Test Conducted.

\begin{tabular}{lll}
\hline Language Competencies & t-test & Interpretation \\
\hline a. Capitalization & 0.82 & Not Significant \\
b. Punctuation & 0.56 & Not Significant \\
c. Grammar & 0.24 & Not Significant \\
d. Sentence Structure & 0.20 & Not Significant \\
e. Word Usage & 0.08 & Not Significant \\
f. Combination & 0.51 & Not Significant \\
\hline
\end{tabular}

Critical and tabular value a. $05=1.645$

The outcomes indicate that the null hypothesis affirming that there was no major change in the level of understanding of the respondents in the control and experimental groups in terms of pre-test mean scores was accepted.

Hence, the null hypothesis which states that there is no significant difference on the comparison of the pre-test and post-test of the two groups is rejected along teaching capitalization, punctuation, grammar and sentence structure, while the same hypothesis is not rejected along teaching word usage.

The following discussions are the results of the post-test of the control and experimental groups on the lessons covered: capitalization, punctuation, grammar, sentence structure, and word usage.

Table 7. Post-Test in Teaching Capitalization

\begin{tabular}{llllll}
\hline \multirow{2}{*}{ Rating } & & \multicolumn{2}{l}{ Control } & \multicolumn{2}{c}{ Experimental } \\
\cline { 3 - 6 } & & f & \% & f & $\%$ \\
\hline Outstanding & $(90-100)$ & 12 & 40 & 17 & 57 \\
Very Satisfactory & $(85-89)$ & 13 & 43 & 10 & 33 \\
Satisfactory & $(80-84)$ & 5 & 17 & 3 & 10 \\
Fairly Satisfactory & $(75-79)$ & 0 & 0 & 0 & 0 \\
Did Not Meet Expectations & $(70-74)$ & 0 & 0 & 0 & 0 \\
Total & & 30 & 100 & 30 & 100 \\
Mean & & 89.37 & & 91.03 & \\
Qualitative Description & & Very Satisfactory & Outstanding \\
\hline
\end{tabular}

Presented in Table 7 was the post-test result in teaching capitalization for both control and experimental groups. In the control group, the overall mean rating was 89.37, described as very satisfactory with 12 or $40 \%$ of the students who received an outstanding rating, while 13 or $43 \%$ had a very satisfactory rating and five (5) or $17 \%$ students were satisfactory.

On the other side, the experimental group garnered an overall mean rating of 91.03 , described as outstanding rating with 17 or $57 \%$ of the students in the outstanding level, 10 or
$33 \%$ in the very satisfactory, and three (3) or $10 \%$ was satisfactory.

Table 8. Post-Test in Teaching Punctuation.

\begin{tabular}{|c|c|c|c|c|c|}
\hline \multirow{2}{*}{ Rating } & & \multicolumn{2}{|c|}{ Control } & \multicolumn{2}{|c|}{ Experimental } \\
\hline & & $\mathbf{F}$ & $\%$ & $\mathbf{F}$ & $\%$ \\
\hline Outstanding & $(90-100)$ & 15 & 50 & 19 & 63 \\
\hline Very Satisfactory & $(85-89)$ & 8 & 27 & 9 & 30 \\
\hline Satisfactory & $(80-84)$ & 7 & 23 & 2 & 7 \\
\hline Fairly Satisfactory & $(75-79)$ & 0 & 0 & 0 & 0 \\
\hline $\begin{array}{l}\text { Did Not Meet } \\
\text { Expectations }\end{array}$ & $(70-74)$ & 0 & 0 & 0 & 0 \\
\hline Total & & 30 & 100 & 30 & 100 \\
\hline Mean & & \multicolumn{2}{|c|}{89.83} & \multicolumn{2}{|c|}{91.73} \\
\hline Qualitative Description & & \multicolumn{2}{|c|}{ Very Satisfactory } & \multicolumn{2}{|c|}{ Outstanding } \\
\hline
\end{tabular}

In table 8 , the result shows that the experimental group had a better performance than the control group in the post-test. It means that the students learned or acquired more understanding using the code-switching as a language teaching strategy as they had a chance to better understand or process the lesson.

In the control group, the overall mean rating was 89.83, described a very satisfactory with 15 or $50 \%$ who got an outstanding rating, eight (8) or $27 \%$ was very satisfactory, and seven (7) or $23 \%$ was satisfactory.

In the experimental group, the overall rating was 91.73 with 19 or $63 \%$ of the students who received an outstanding rating while nine (9) or $30 \%$ received a very satisfactory rating and two (2) or $7 \%$ was rated satisfactory.

Table 9. Post-Test in Teaching Grammar.

\begin{tabular}{llllll}
\hline \multirow{2}{*}{ Rating } & & \multicolumn{2}{c}{ Control } & \multicolumn{3}{c}{ Experimental } \\
\cline { 3 - 6 } & & $\mathbf{f}$ & $\mathbf{\%}$ & $\mathbf{f}$ & $\mathbf{\%}$ \\
\hline Outstanding & $(90-100)$ & 11 & 37 & 15 & 50 \\
Very Satisfactory & $(85-89)$ & 12 & 40 & 11 & 37 \\
Satisfactory & $(80-84)$ & 7 & 23 & 4 & 13 \\
Fairly Satisfactory & $(75-79)$ & 0 & 0 & 0 & 0 \\
Did Not Meet Expectations & $(70-74)$ & 0 & 0 & 0 & 0 \\
Total & & 30 & 100 & 30 & 100 \\
Mean & & 88.77 & & 90.33 & \\
Qualitative Description & & Very Satisfactory & Outstanding \\
\hline
\end{tabular}

Table 9 shows the mean rating and qualitative description in the post-test on grammar of the control and experimental groups.

It can be gleaned in the table that the two groups had a remarkable increase compared to its pre-test. In the control group, the overall mean rating was 88.77 , described as very satisfactory with 11 or $37 \%$ of the students who received an outstanding rating, while 12 or $40 \%$ received very satisfactory and seven (7) or $23 \%$ received a satisfactory rating.

Meanwhile, in the experimental group, the overall mean rating was 90.33 , described as outstanding with 15 or $50 \%$ outstanding, 11 or $37 \%$ very satisfactory and four (4) or $13 \%$ satisfactory. 
Table 10. Post-Test in Teaching Sentence Structure.

\begin{tabular}{llllll}
\hline \multirow{2}{*}{ Rating } & & \multicolumn{2}{c}{ Control } & \multicolumn{2}{c}{ Experimental } \\
\cline { 3 - 6 } & & f & \% & f & $\%$ \\
\hline Outstanding & $(90-100)$ & 9 & 30 & 13 & 43 \\
Very Satisfactory & $(85-89)$ & 15 & 50 & 10 & 33 \\
Satisfactory & $(80-84)$ & 6 & 20 & 7 & 24 \\
Fairly Satisfactory & $(75-79)$ & 0 & 0 & 0 & 0 \\
Did Not Meet & $(70-74)$ & 0 & 0 & 0 & 0 \\
Expectations & & 30 & 100 & 30 & 100 \\
Total & & 88.40 & & 89.30 \\
Mean & & \multicolumn{3}{c}{ Very Satisfactory } & \multicolumn{3}{c}{ Very Satisfactory } \\
Qualitative Description & & \multicolumn{3}{c}{} \\
\hline
\end{tabular}

Table 10 shows the overall mean rating and qualitative description in the control and experimental group in the posttest on the sentence structure.

In the control group, the overall mean rating was 88.40 , described as very satisfactory with nine (9) or 30\% who got an outstanding rating, 15 or $50 \%$ was very satisfactory, and six (6) or $20 \%$ was satisfactory. In the experimental group, the overall rating was 89.30 with 13 or $43 \%$ of the students who received an outstanding rating, while 10 or $33 \%$ received a very satisfactory rating and seven (7) or $24 \%$ was rated satisfactory.

The result shows that the experimental group had a better performance than the control group in the post-test.

Table 11. Post-Test in Teaching Word Usage.

\begin{tabular}{llllll}
\hline \multirow{2}{*}{ Rating } & & Control & \multicolumn{2}{c}{ Experimental } \\
\cline { 3 - 6 } & & $\mathbf{f}$ & $\mathbf{\%}$ & $\mathbf{f}$ & $\mathbf{\%}$ \\
\hline Outstanding & $(90-100)$ & 12 & 40 & 14 & 47 \\
Very Satisfactory & $(85-89)$ & 12 & 40 & 11 & 37 \\
Satisfactory & $(80-84)$ & 6 & 20 & 5 & 16 \\
Fairly Satisfactory & $(75-79)$ & 0 & 0 & 0 & 0 \\
Did Not Meet & $(70-74)$ & 0 & 0 & 0 & 0 \\
Expectations & & 30 & 100 & 30 & 100 \\
Total & & 89.20 & & 89.90 & \\
Mean & & \multicolumn{3}{l}{ Very Satisfactory } & Very Satisfactory \\
Qualitative Description & & \multicolumn{4}{c}{}
\end{tabular}

Table 11 shows the overall mean rating and qualitative description in the control and experimental group in the posttest on the word usage.

Table 12. $t$-Tests on the Difference between the Control and Experimental Groups on the Post-Test Conducted.

\begin{tabular}{lll}
\hline Language Competencies & t-test & Interpretation \\
\hline a. Capitalization & 3.23 & Significant \\
b. Punctuation & 2.06 & Significant \\
c. Grammar & 1.72 & Significant \\
d. Sentence Structure & 1.89 & Significant \\
e. Word Usage & 0.82 & Not Significant \\
f. Combination & 2.89 & Significant \\
\hline
\end{tabular}

Critical and tabular value a. $05=1.645$

In the control group, the overall mean rating was 89.20 , described as very satisfactory with 12 or $40 \%$ of the students who received an outstanding rating, while 12 or $40 \%$ had a very satisfactory rating and six (6) or $20 \%$ students were satisfactory. On the other hand, the experimental group garnered an overall mean rating of 89.90 , described as outstanding rating with 14 or $47 \%$ of the students in the outstanding level, 11 or $37 \%$ in the very satisfactory, and five (5) or $16 \%$ was satisfactory.

Both groups were qualitatively described as very satisfactory.

Table 12 shows the t-values between the control group and the experimental group of the five language competencies tested.

These findings indicate that the mean comparison between the two groups yielded significant difference in favor of experimental group. This implies that the use of codeswitching as a language teaching strategy anchored on the grammar-translation method is also a good strategy in teaching the English subject.

As reflected in the table, in teaching word usage, the computed t-value of 0.82 is not significant at 0.05 level. This means that both groups had similar performance in the said lesson. Both lecture and code-switching strategy were found to be effective in this particular language competency.

\subsection{The Qualitative Analysis of the Data from Lesson}

\section{Observations and Teacher Interview}

All the transcribed lessons served as focal points in the analysis of the qualitative data. However, reference was also made to the other lessons not transcribed and some examples drawn from them necessary. The lessons were mainly characterized by the teachers' discourse and there were very few learners' discourse. The lessons were also teachercentered; that is, the teacher was the main speaker while the learners were participants with invitations by the teacher to respond to questions. Their responses were brief in the form of either words or phrases or a short sentence. At times, the learners responded in chorus using short responses such as 'oo' (yes) or 'diri' (no) followed by 'miss' or 'ma'am'. The favourable answer implied that the students were following what was being said or that they agreed with the instructor while negation implied disparity or that they were not following what was being said. Where there were learner responses, they were, in most cases, barely audible. Although this was a setback, it did not adversely affect the result of the study because it provided an accurate picture of the language situation in the classroom. The classroom observations also included a description of what visually transpired in the classroom. The notes were used as well to provide descriptions of the visible occurrences and were included in the transcriptions. These occurrences included gestures or mumbling by any of the respondents. Furthermore, as noted by Fasold (1984: 152, in Strydom, 2002: 85), 'observation' refers to the recording of people's activities by the researcher whilst watching them. It enabled the researcher to observe the conduct of the participants, and later to interpret the observations made in relation to the phenomenon being researched, namely code-switching.

During the class observation, the researcher observed that in Class B, both teachers and students were eager in discussing the lesson. The researcher perceived that most of the time, the English language and the native tongue or the 
Filipino language was switched to explain things all throughout the discussion. It showed as well that the students were able to speak English but when the teacher tried to speak the vernacular, they were also influenced by it which means that the teacher was the one who influenced them to switch and play a vital role in really learning the English language. The discussion below displays the prevalence of code-switching in the classroom.

\section{Lesson: Parallel Structure}

Teacher: Okay, now let's talk about another topic $\backslash$

today. Let me ask you, what do you mean by

parallel?

Students: (answered in chorus)

Student: bagis

Teacher: We're talking about parallel here? Okay, what kind of line?

Student: Straight... tadong.

Teacher: Straight....ano pa?

Student: Balabag... vertical.

Teacher: Okay, what if we're talking about sentences?

What do you mean by parallel or parallel

structure?

Student: Pagkakapareho, Ma'am?

Teacher: Exactly. For example masiring kamo... Ana

is... honest...pretty... and beautiful.

Students: (Read in chorus)

Teacher: What describes Ana?

Students: honest, pretty, and beautiful.

Teacher: What part of speech are these?

Students: (Answered in chorus) Adjective, Ma'am.

Teacher: Very good. Now, since we say that parallel

structure is about pagkakapareho, pareho,

Can we say that this sentence has a parallel

structure?

Students: Yes, Ma'am.

Teacher: Why?

Students: Because they are all adjectives.

Teacher: That is right!

The above conversation during the English language lesson proves that not only the teacher influenced the students to engage into switching, but she also liked to switch from English language to her vernacular, Waray-waray. From the conversation, the teacher said, "Let me ask you, what do you mean by parallel?" It was evident that the students just translated the English word to their vernacular which manifests that even though the teachers ask in English, still students will answer it in their vernacular or try to translate it in their native tongue. Also, it was apparent that whenever the teacher code-switches from English to Waray-waray, that is when the students understand better.

Lesson: Subject-Verb Agreement

Teacher: For example, either my sisters or my mom.

Ano it singular? Ano it nearest?

Students: (In chorus) Ma'am my mom iton singular. Teacher: Okay, my mom is singular...so an aton gagamiton na verb is...

Students: singular.
Teacher: Alright. But what if masiring either my mom or my sisters 'has have' set in.

Students: Ma'am iton have.

Teacher: Have kamo an harani, an plural. Got it? Nakaintindi?

Students: Yes Ma'am!

The instructor makes a comment in English in this instance and moves to Waray-waray, asking a question to students who know very well that the answer is straightforward. Expectedly, in Waray-waray, the learners react. This technique was often used and it allowed the instructor to inspire learners in the lesson to engage and pay attention. In addition, both English and Waray-waray were used by the instructor in Class 2 to describe and clarify the subject matter

In a classroom setting, the prevalence of code-switching turns out to be a normal phenomenon. With special studies focused on the essence of code-switching and its relevance in both social and scholarly environments, the phenomenon continues to attract interest.

In the data gathered during the interview of the teacherrespondents, they both agreed that code-switching has a significant effect in terms of understanding instruction. The observation shows the difference between the two groups. In Class A, the control group, the class seemed to be passive participants due to the restrictions of expressing themselves and lack of proficiency of the English language. They were not able to grasp proper words that would fit to what they wanted to say. On the contrary, the class in the experimental group was more active in participating in the class discussion because they were able to express themselves with the language they are using. Further, the information is clear and understandable because the students knew the equivalent of those unfamiliar words in Filipino or Waray-waray. In the interview, according to the Teacher 2, she preferred to use the code-switching in teaching English and really had a significant implication in the learning process of the students. On the other hand, Teacher 1, though exposed in the English only policy, agreed that code-switching was advantageous in the teaching and learning procedure. An extract of the interview is given below:

\section{Interview}

In What do you think about the use of code-switching in English Language Teaching classrooms?

T2 I think it's effective as long as you know your learners you can do better and you can use any devices for way of communicating with your students.

In How often should a Waray-waray/Filipino be used in English Language Teaching classrooms?

T2 I think it matters on your learners' capability to understand or learn different situations, have different way of learning so there are some things that you have to do like for example if it's mostly in lower years or lower level, they have mostly difficulties in understanding English as often as you have to transcode into code-switching.

In If you code-switch in your classroom, when and why do you do so?

T2 As I have said, there are students who are not really fast 
in learning the English language so you have to transcode, you have to make necessary adjustments on how they can learn.

In Do you see any advantages in your code- switching in classrooms, why?

T2 Yes, of course. There are lots of advantages because it is your way of communicating on how you can teach your students effectively.

In this interview, Teacher 2 states that there are lots of advantages in using a code-switching strategy especially in communicating to the students to ensure comprehension enhancement in their part. However, she also identified disadvantages like students may have lesser chance of learning the English language specifically when not used. As much as possible, the use of the English language be maximized. She also added to encourage the learners to speak English to be fluent and ultimately, master the language.

On the other side, Teacher 1 also agrees that codeswitching contributes to the development of a learner to comprehend the lesson easier. Though the teacher was assigned in the English only policy technique, she also believed that there is a comparable difference when a teacher code-switches in the classroom. The extract below displays a deeper thought of code-switching as a language teaching strategy.

Interview:

In If your students find difficulty understanding what you are talking about, say explaining a grammar point, assigning homework or an activity, would you employ our L1 in this case? If not, why?

T1 I would employ Filipino or Waray-waray to aid in understanding the topic.

In Could you please explain why your code- switching contributes to or hinders learners' language learning?

T1 I think it contributes more than hinders because learners in learning the language. Students who exposed to English as a medium of instruction are more likely to learn the language better.

In Do you use English when discussing all kinds of topics? Or you employ L1 for specific topics? Like what?

T1 Yes... I use English in my discussion though I would employ Waray- waray so students can see the relation of the topics to the local setting.

In When explaining unfamiliar concepts, or when there are no similar words in English, which code do you employ? And why?

T1 I think its English that should be the medium of instruction but we can employ Waray-waray in explaining difficult topics or lessons.

According to Teacher 1 who employed the English-onlypolicy strategy, she would use code-switching strategy especially when a student finds difficulty understanding difficult words or discourse. She also agreed that whenever there are grammar points or activities or homework, there is a need to code-switch knowing that some students do not pay attention to the instructions due to the barrier of the language. Students also tend to always agree or resort to the affirmative side to every instructions or discussions of the teacher even though they did not even understand it. That is why, English teachers really need to look after the welfare of the students' comprehension by employing lots of strategies or techniques. One for sure is the use of code-switching. In the question:

In Do you use English when discussing all kinds of topics? Or you employ L1 for specific topics? Like what?(36-37)

T1 Yes... I use English in my discussion though I would employ Waray- waray so students can see the relation of the topics to the local setting.(38-39)

This manifests that, even though the Department of Education mandated that the English language should be used as a medium of instruction, teachers, specifically, English teachers, cannot go away from translating it or switching it to Filipino or Waray-waray. This part suggests that Teacher 1 will use the vernacular to the extent that the students will understand the lesson without compromising or alleviating English as a subject and as a medium of instruction.

This study, then, denotes that there is a need to apply the code- switching strategy in view of the fact that there are students who cannot readily speak in the classroom discussions because they are hesitant about speaking in the second language. Moreover, there are also students who cannot understand the words in English because they do not know its equivalent or translation in their native language. On the other hand, if the code-switching strategy is applied, the students will tend to have a more developed English vocabulary and comprehension skills before they reach higher levels because the technique allots more time for the students to encounter foreign words while these are being translated into the Waray-waray/Filipino language. This study also concludes that the teachers must have the freedom in choosing the technique that they want to use, whether code-switching or English only policy technique, because they are the ones who know best what is best for their students for they know their capabilities, strengths and weaknesses and know the appropriate method needed to meet the learning objectives.

\section{Summary of Findings, Conclusions and Recommendations}

This chapter summarizes the findings on the experiments, presents conclusions arrived at, and the recommendations for future action.

\subsection{Summary of Findings}

This study investigated the effectiveness of code-switching as a language teaching strategy based on the grammartranslation method for comprehension enhancement to the Grade 7 students of Tanauan School of Craftsmanship and Home Industries, Tanauan, Leyte during the School Year 2018-2019.

The study used an experimental method of research. There were two groups under study: the control group who were 
exposed to the English-only-policy method and the experimental group who were exposed to the code-switching strategy.

A 50-item teacher-made test was administered to the subjects of the study during the pre- and post-tests. The data were statistically treated using the mean, standard deviation, and t-tests of dependent and independent samples.

The data gathered were analyzed with the use of 0.05 level of significance.

The study was conducted at Tanauan School of Craftsmanship and Home Industries, Tanauan, Leyte, from February 12, 2019 to March 12, 2019 for a period of four (4) weeks.

The respondents of the study were 60 Grade 7 students comprising four heterogeneous sections namely: Titan (15), Enceladus (15), Io (15) and Europa (15) at Tanauan School of Craftsmanship and Home Industries.

Since the experiment investigated the effectiveness of codeswitching as a language teaching strategy based on the grammar-translation method for comprehension enhancement, there was a need to measure achievement through a 50 -item pre-test and post-test. Mean ratings of the students in both groups in the achievement test were analyzed.

The following relevant findings are thus summarized.

1. The achievement of the students in the pre-test of the control group along the identified language competencies.

In teaching capitalization, the pre-test achievement of the students in the control group yielded a mean score of 80.83 , interpreted as satisfactory.

In teaching punctuation, the pre-test achievement of the students in the control group yielded a mean score of 79.17 , interpreted as fairly satisfactory.

In teaching grammar, the control and experimental groups shared the same mean score of 78.17 , interpreted as fairly satisfactory.

In teaching sentence structure, the pre-test achievement of the students in the control group yielded a mean score of 78.50 , interpreted as fairly satisfactory.

In teaching word usage, the pre-test achievement of the control group yielded a mean score of 80.17 , interpreted as satisfactory.

2. The achievement of the students in the pre-test of the experimental group along the identified language competencies.

In teaching capitalization, the pre-test achievement of the students in the experimental group yielded a mean score of 79.33, interpreted as fairly satisfactory.

In teaching punctuation, the pre-test achievement of the students in the experimental group yielded a mean score of 78.33, also fairly satisfactory.

In teaching grammar, the control and experimental groups shared the same mean score of 78.17, interpreted as fairly satisfactory, in the pre-test achievement which denotes that the two groups are equal in their grammar skills as both groups have the same level of comprehension.

In teaching sentence structure, the pre-test achievement of the students in the experimental group yielded a mean score of 78.33, interpreted as fairly satisfactory.

In teaching word usage, the pre-test achievement of the experimental group yielded a mean score of 79.83, interpreted as fairly satisfactory.

3. The significant difference between the control and experimental group along the language competencies.

In the combination of the five language competencies, the pre-test achievement of the students in the control group yielded a mean score of 80.50 , interpreted as satisfactory and the same mean score of 80.50 , interpreted as satisfactory was earned by the experimental group. The computed t-values of the identified language competencies were all not significant.

4. The achievement of the students in the post-test of the control group along the identified language competencies.

In teaching capitalization, the post-test achievement of the students in the control group yielded a mean score of 89.37 , interpreted as good. In teaching punctuation, the post-test achievement of the students in the control group yielded a mean score of 89.83 , interpreted as very satisfactory.

In teaching grammar, the post-test achievement of the students in the control group yielded a mean score of 88.77 , interpreted as very satisfactory.

In teaching sentence structure, the mean score of the control group was 88.40 , interpreted as very satisfactory.

Lastly, in the word usage, the post-test achievement of the students in the control group yielded a mean score of 89.20 , interpreted as very satisfactory.

5. The achievement of the students in the post-test of the experimental group along the identified language competencies.

In teaching capitalization, the post-test achievement of the students in the experimental group yielded a mean score of 91.03, interpreted as outstanding. In teaching punctuation, the post-test achievement of the students in the experimental group earned a mean score of 91.73, interpreted as outstanding.

In teaching grammar, in the post-test achievement of the students in the experimental group, they got a mean score of 90.33 , interpreted as outstanding.

In teaching sentence structure, the experimental group yielded a mean score of 89.30 , interpreted as outstanding, and was gained by the students. In the word usage, the posttest achievement of the students in the experimental group, the students got a mean score of 89.90 , interpreted as very satisfactory.

6. The significant difference between the control and experimental group along the language competencies.

In the combination of the five language competencies, the post-test achievement of the students in the control group yielded a mean score of 89.67, interpreted as very satisfactory, while in the experimental group, the students got a mean score of 91.53, interpreted as outstanding.

7. Teaching-learning experiences of teachers in using code-switching strategy

The teaching and learning experiences of the teachers in 
using code- switching has proven that the development of English as a second language can be facilitated in students through code-switching in which teachers used codeswitching strategy to enhance comprehension skills.

\subsection{Conclusions}

From the findings of the study, the following were the drawn conclusions:

1. The achievement of the control group in the pretest on the language competencies: teaching capitalization was satisfactory, teaching punctuation, grammar and sentence was fairly satisfactory and teaching word usage was satisfactory, while the combination was satisfactory.

2. The achievements of the experimental group in the pretest: teaching capitalization was satisfactory, teaching punctuation, grammar and sentence was fairly satisfactory and teaching word usage was satisfactory, while the combination was satisfactory.

3. The computed t-values were all not significant.

4. The achievement of the control group in the post-test for all five competencies was very satisfactory.

5. On the other hand, in the experimental group, topics on teaching capitalization, punctuation, and grammar received an outstanding rating, and teaching sentence structure and word usage garnered a very satisfactory rating. The combination of the five language competencies was outstanding.

6. There was a significant difference on the level of comprehension between the control and experimental groups in teaching capitalization, punctuation, grammar, sentence structure, and word usage, and combination during the post-test, however, teaching word usage did not yield significant results.

7. The teaching and learning experiences of the teachers in using code-switching has proven that the development of English as a second language can be facilitated in students through code-switching in which teachers used codeswitching strategy to enhance comprehension skills. Therefore, as analyzed in this study, taking into account the data obtained on the effectiveness of code-switching as a language teaching strategy based on the grammartranslation method for comprehension enhancement, it can be suggested that code- switching is not just a mere alternation or use of two or more languages [13] rather, it is the intentional choice of language which enhances the classroom environment on many sides and delivers the message better than one could do in another language.

\subsection{Recommendations}

Based on the findings and conclusions of this study, the researcher recommends the following:

1. Since the code-switching as a language teaching strategy anchored on the grammar-translation method for comprehension enhancement was shown to be effective, the researcher recommends using it as a technique in teaching especially on the basic language competencies.
2. It may be recommended that effective and deliberate uses of code-switching, as teachers and students, augments learning, helps students express themselves better, helps avoid confusions in parts of delivering the lesson content.

3. English teachers must be reoriented in diagnosing students' skills in the language competencies so that they can effectively apply this to future use.

4. English teachers must be able to know what technique or strategy to use with respect to the comprehension level of the students.

5. Teachers' switching to the vernacular/Filipino may be utilized for sociolinguistics and linguistics purposes and can be academically purposeful when used to compare and contrast the two languages.

6. DepEd should not only consider English-only-policy as a medium of instruction but also code-switching technique especially when explaining difficult words while the students are obliged to still use the language in explaining out things.

7. Further research is necessary to establish the effectiveness of code-switching technique on the students' comprehension level.

To sum it up, this study supports the claim that the Englishonly-policy for content-based instruction seems impractical and ineffective in countries where English is the second or foreign language. The findings offer strong indications that code-switching by teachers and students have a strong impact when it comes to the comprehension skills of the learners. Therefore, there is a need to consider the use of code-switching as a technique in the teaching and learning process especially when explaining difficult lessons or situations.

\section{References}

[1] Abad, L. (December, 2005). Code-switching in the classroom: A clash of two languages Faculty Research Journal of Miriam College. 36-52.

[2] Auer, P. 1984. On the Meaning of Conversational Code Switching. Interpretive sociolinguistics 87-112.

[3] Auerbach, E. R. 1993. Re-examining English Only in the ESL classroom. Teachers of English to Speakers of other Languages, Inc 27 (1): 9-32.

[4] Bautista, M. L. S. (1980). The Filipino bilingual's competence: a model based on an analysis of Tagalog-English codeswitching (Canberra, A. C. T., Australia: Dept. of Linguistics, Research School of Pacific Studies, Australian National University).

[5] Bernardo, A. B. I. (2005). Bilingual code-switching as a resource for learning and teaching: Alternative reflections on the language and education issue in the Philippines. Manila, Philippines. Linguistic Society of the Philippines.

[6] Blom, J. P., \& Gumperz, J. J. (1972). Social meaning in linguistic structures: Code-switching in Norway. In L. Wei (Ed.), The bilingualism reader, (pp. 111-136). London: Routledge. 
[7] Cohen, A. and Macaro, E. (2007). Language Learner Strategies: 30 Years of Research And Practice. Oxford: Oxford University Press.

[8] Cook, V. (2001). Using the first language in the classroom. The Canadian Modern Language Review, 57 (3), 402-423.

[9] Downes, W. 1998. Language and Society. 2nd edition. Cambridge: Cambridge University Press. pp. 80-92.

[10] Finlayson, R and Slabbert, S. 2002. Code-switching in South African townships. In Mesthrie, R. Language in South Africa. New York: Cambridge University Press. pp. 235-257.

[11] Finlayson, R., Calteaux, K. \& Myers-Scotton, C. (1998). Orderly mixing and accommodation in South African codeswitching. Journal of Sociolinguistics, 2 (3), 395-420.

[12] Garcia, O. and Wei, L. 20113. Translanguaging: Language, Bilingualism and Education. Basingstoke: Palgrave Macmillan.

[13] Grosjean, François. 2012. Bilingual: Life and Reality. Cambridge, MA: Harvard University Press.

[14] Gulzar, M. A. 2010. Code Switching: Awareness about its Utility in Bilingual Classrooms. Bulletin of Education and Research. 32.2.

[15] Gumperz, John Joseph. 1982. Discourse Strategies. Cambridge: Cambridge University Press.

[16] Guthrie, M. 1984. Contrasts in Teachers' Language Use in a Chinese-English. In J. Handscombe, R. A. Ovem and B. P. Taylor (eds.). On TESOL 1983: the question of control. Washington, D.C.: TESOL. pp. 39-52.

[17] Hamers, J. F and Blanc, H. A. 2000. Bilinguality and bilingualism. 2nd edition. Cambridge: Cambridge University Press. Pp. 258-272.

[18] Harmer, J. (2007). The practice of English language teaching. (4. [rev.] ed.) Harlow: Longman.

[19] Kachru, Y. (2009). World Englishes and language education. In S. J. Nero (Ed.), Dialects, Englishes, creoles and education. ESL \& applied linguistics professional series, (pp. 19-37). New York: Routledge, Taylor and Francis Group.

[20] Kroeger, P. (1993). Phrase Structure and Grammatical Relations in Tagalog (Center for the Study of Language (CSLI)).

[21] Lewis, M. Paul, Gary F. Simons, and Charles D. Fennig (eds.), (2013). Ethnologue:

[22] Languages of the World, Seventeenth edition. Dallas, Texas: SIL International. Online version: http://www.ethnologue.com.

[23] Li, W. (1998). The 'Why' and 'How' Questions in the Analysis of Conversational Codeswitching. In P. Auer. Code-Switching in Conversation: Language, Interaction, and Identity. London: Routledge. pp. 156-76.

[24] Lin, Angel. 2013. Classroom code-switching: Three decades of research. Applied Linguistics Review, 4 (1): 195-218.

[25] Macaro, E. (2001). Analysing student teachers' codeswitching in foreign language classrooms: Theories and decision making. The Modern Language Journal, 85 (4), 531- 548.
[26] Mackey, William. 2003. 'Bilingualism and Multilingualism,' to appear in Ulrich Ammon, Norbert Dittmar, and Klaus J. Mattheier (eds.), Sociolinguistics/Soziolinguistik (second edition). Berlin: Walter de Gruyter.

[27] Matila, R. (2009). Decoding the switch: The functions of code switching in the Classroom education quarterly. U. P. College of Education, 67 (1), 44-61.

[28] Muysken, Pieter. 1995. "Code-switching and grammatical theory." In One Speaker, Two Languages: Cross-disciplinary perspectives on code-switching, edited by Milroy, Lesley and Pieter Muysken, 177-198. Cambridge: Cambridge University Press.

[29] Myers-Scotton, C. 1993. Social Motivations for Code Switching. Evidence from Africa. Oxford: Clarendon Press.

[30] Myers-Scotton, C. (1988). Codeswitching as indexical of social negotiations. In $\mathrm{M}$.

[31] Heller (Ed.), Codeswitching: Anthropological and sociolinguistic perspectives (pp. 151- 86). Berlin: Mouton de Gruyter.

[32] Nilep, C. 2006. Code Switching in Socio-cultural Linguistics. Colorado research in Linguistics. 2006 (19): 1-18.

[33] Olmo-castillo, W. N. (2014). Teachers' attitudes towards code switching within a bilingual classroom. (Master's thesis).

Retrieved from $\mathrm{http}$ //digitalcommons.brockport.edu/cgi/viewcontent.cgi?artic $\mathrm{le}=1394 \&$ context $=$ ehd theses

[34] Poplack, Shana V. 1978. Syntactic structure and social function of code-switching. New York: Centro de Estudios Puertorriqueños.

[35] Qing, X. (2010). To switch or not to switch: Examine the code-switching practices of teachers of non-English majors. Canadian Social Science, 6 (4), 109-113.

[36] Schendl, H., \& Wright, L. (red.) (2011). Code-switching in early English. Berlin: De Gruyter Mouton.

[37] Simon, D. (2001). Towards a new understanding of codeswitching in the foreign language classroom. In $\mathrm{R}$. Jacobson (Ed.), Codeswitching worldwide II. (pp. 311-342). Berlin: Mouton de Gruyter.

[38] Thompson, Roger M. (2003) Filipino English and Taglish Language switching from multiple perspectives. Philadelphia: John Benjamin Publishing Company.

[39] Vygotsky, L. S. (1986). Thought and language. ([Rev. ed.]). Cambridge, Mass.: MIT Press.

[40] Auer, P. 2002. A Post Script: Code Switching and Social identity. Journal of pragmatics 37: 403-410.

[41] Brock-Utne, B. and Holmarsdottir, H. B. 1997. Language policies and practices in Tanzania and South Africa: problems and challenges: International journal of Educational Development 24 (2004): 67-83.

[42] Eldridge, J. (1996). Code-switching in a Turkish secondary school. ELT Journal, 50 (4), 303- 311.

[43] Fishman, Joshua A. 1967. "Bilingualism with and without Diglossia; Diglossia with and without Bilingualism." In Journal of Social Issues XXIII, No. 2, 1967. 
[44] Gonzales, W. D. W. 2016. "Trilingual Code-switching Using Quantitative Lenses: An Exploratory Study on Hokaglish.'In Philippine Journal of Linguistics, 47, 106-128.

[45] Hughes, C. E., Shaunessy, E. S., Brice, A. R., Ratliff, M. A., \& McHatton, P. A. (2006). Code switching among bilingual and limited proficient students: Possible indicators of giftedness. Journal for the Education of the Gifted, 30 (1), 7-28.

[46] Macaro, E. (2001). Analysing student teachers' codeswitching in foreign Languages Classrooms: Theories and decision making. Modern Languages Journal, 85, 531-548.

[47] Bugayong, L. Taglish and the social role of code-switching in the Philippine. Philippine Journal of Linguistics, 4, 1-19.

[48] Polio, C. G. and Duff, P. A. 1994. Teachers' Language Use in University Foreign Language Classrooms: A Qualitative Analysis of English and Target Language Alternation. The Modern Language Journal 78 (3) 313-326.

[49] Baquita, Michael. "Identifying Influences on Teaching Strategies and Attitudes Among Secondary Teachers," Unpublished Master's Thesis. Samar State University, Catbalogan, Samar, 2004.

[50] Dahmer, Margaret. "Phonological Awareness in the Kindergarten Classroom: How Do Teachers Perceive This Essential Link From Oral Communication to Reading Skill Development." Unpublished Disseration, Liberty University, 2010.
[51] Montances, Wilfredo L. "Factors associated with the Performance of Classroom Teachers: Their Implications to Educational Management," Unpublished Master's Thesis. Samar College, Catbalogan, Samar, 2004.

[52] Tonelete, Lea M. "Teachers' Performance and Achievement of Grade VI Pupils in English, Science, and Mathematics. A Correlation," Unpublished Master's Thesis. Samar College, Catbalogan, Samar, 2003.

[53] Chua, Y. (2008, February 6) DepEd adopts “Textbook Walks". Retrieved March 8, 2009, from GMA News Philippines Online: http://www.gmanews.tv/story/98684/DepEd-adoptsTextbook-Walk.

[54] Department of Education, Republic of the Philippines. 2013. "K to 12 Curriculum Guide: Mother Tongue. "Accessed November $16,2016$. http://www.deped.gov.ph/sites/default/files/Final Mother Tongue Grades 1-3 01.21.2014_pdf.

[55] Huang, Y. P. P. (2008). Language use of beginning students in a Taiwanese English immersion preschool. Retrieved on July 11, 2015 from http://paperedu.org/docs/index- 12606.html.

[56] https://www.thoughtco.com/code-switching-language-1689858.

[57] Tagalog language. (2009). In Encyclopedia Britannica. Retrieved April, 2009, from Encyclopedia Britannica Online: http://www.britannica.com/EBchecked/topic/580260/Tagalogl anguage. 